\title{
Skin Appendage Hamartoma
}

National Cancer Institute

\section{Source}

National Cancer Institute. Skin Appendage Hamartoma. NCI Thesaurus. Code C5562.

A hamartoma characterized by localized malformation of one or more of the skin appendages; including sweat glands, sebaceous glands, and hair follicles. 